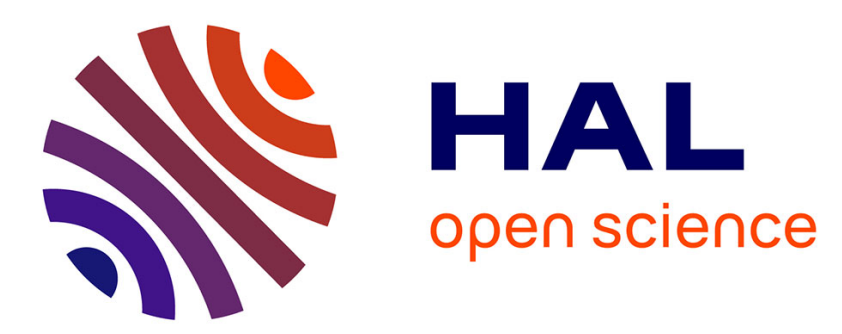

\title{
In-core heat distribution control for adaptive damping and stiffness tuning of composite structures
}

Pauline Butaud, D Renault, Benoît Verdin, Morvan Ouisse, Gael Chevallier

\section{To cite this version:}

Pauline Butaud, D Renault, Benoît Verdin, Morvan Ouisse, Gael Chevallier. In-core heat distribution control for adaptive damping and stiffness tuning of composite structures. Smart Materials and Structures, 2020, 29 (6), pp.065002 (11). hal-03020548

\section{HAL Id: hal-03020548 \\ https://hal.science/hal-03020548}

Submitted on 23 Nov 2020

HAL is a multi-disciplinary open access archive for the deposit and dissemination of scientific research documents, whether they are published or not. The documents may come from teaching and research institutions in France or abroad, or from public or private research centers.
L'archive ouverte pluridisciplinaire HAL, est destinée au dépôt et à la diffusion de documents scientifiques de niveau recherche, publiés ou non, émanant des établissements d'enseignement et de recherche français ou étrangers, des laboratoires publics ou privés. 
ACCEPTED MANUSCRIPT

\section{In-core heat distribution control for adaptive damping and stiffness tuning of composite structures}

To cite this article before publication: Pauline Butaud et al 2020 Smart Mater. Struct. in press https://doi.org/10.1088/1361-665X/ab802a

\section{Manuscript version: Accepted Manuscript}

Accepted Manuscript is "the version of the article accepted for publication including all changes made as a result of the peer review process, and which may also include the addition to the article by IOP Publishing of a header, an article ID, a cover sheet and/or an 'Accepted Manuscript' watermark, but excluding any other editing, typesetting or other changes made by IOP Publishing and/or its licensors"

This Accepted Manuscript is @ 2020 IOP Publishing Ltd.

During the embargo period (the 12 month period from the publication of the Version of Record of this article), the Accepted Manuscript is fully protected by copyright and cannot be reused or reposted elsewhere.

As the Version of Record of this article is going to be / has been published on a subscription basis, this Accepted Manuscript is available for reuse under a CC BY-NC-ND 3.0 licence after the 12 month embargo period.

After the embargo period, everyone is permitted to use copy and redistribute this article for non-commercial purposes only, provided that they adhere to all the terms of the licence https://creativecommons.org/licences/by-nc-nd/3.0

Although reasonable endeavours have been taken to obtain all necessary permissions from third parties to include their copyrighted content within this article, their full citation and copyright line may not be present in this Accepted Manuscript version. Before using any content from this article, please refer to the Version of Record on IOPscience once published for full citation and copyright details, as permissions will likely be required. All third party content is fully copyright protected, unless specifically stated otherwise in the figure caption in the Version of Record.

View the article online for updates and enhancements. 


\begin{abstract}
In this work, a smart composite structure with damping and stiffness control ability is proposed. The multilayered arrangement has a shape memory core, whose damping and stiffness are tuned by temperature control. The structure is divided in several zones, each of them can be heated in real time using temperature regulation to reach the expected mechanical properties provided by the strong temperature and frequency dependency of the stiffness and loss factor of the viscoelastic core. The heat flux, which is used to tune the mechanical properties, is provided by copper tracks printed on an electronic board used as skin of the sandwich. The paper presents a model-based design process, including thermal and mechanical simulations, providing the gradient temperature fields which are required to obtain a specific damping and stiffness. Experimental tests are finally presented, considering three configurations with various temperature sets corresponding to three different compromises between static stiffness and dynamic damping.
\end{abstract}

Keywords: adaptive damping, adaptive stiffness, temperature based vibration control, shape memory polymer

\title{
1. Introduction
}

The combination of materials in composite structures can provide new properties which are not easy, or even impossible, to obtain with classical materials. Among others, high stiffness and low mass composite structures are widely used in transports industry. They can however exhibit quite poor vibroacoustic performances. In order to increase their damping properties, viscoelastic materials are good candidates, because of their low cost and robustness $[1,2]$. They are typically used in multilayered composites [3], in particular as cores in order to maximise the shear strain, hence inducing increase of dissipation [4]. A lot of research efforts have been devoted to the optimization of the design of multilayered composites $[5,6,7,8,9]$ : geometry, materials and boundary 


\section{In-core heat distribution control for adaptive damping and stiffness tuning of compositestructures 2}

conditions may have strong impact on the energy dissipation and should be properly chosen. In particular, glass transition of polymer materials can be a key factor for high damping performances: viscoelastic materials that exhibit a fast transition between the rubbery and the glassy states are particularly interesting because of their high loss factor values at glass transition $[10,11]$. However, since the viscoelastic properties are dependent on both frequency and temperature $[12,1,13]$, it is of first importance to take into account the temperature effects for the design of composite structures whose damping properties are provided by polymer materials $[14,15,16,17,18]$, and the materials have to be chosen in adequacy with the operating temperature ranges in order to guarantee the robustness of the design [19].

In this work, it is proposed to take advantage of the temperature dependency of the viscoelastic properties in order to control the stiffness and the damping of composite structures. This concept has been proposed in [20], in which an homogeneous temperature field is imposed: the structure is placed in a thermal chamber to this end. Very high damping levels are then obtained when the temperature is close to the glass transition of the core material. However, a reduction of the static stiffness is induced by the homogeneity of the temperature field, because of the fall of stiffness around the glass transition, which affects the whole structure. The same strategy has been applied in [21] to obtain a metamaterial with two states by controlling its stiffness, but also in [22] to enhance the absorption in an acoustic black hole through damping control. In the work presented in this paper, the concept is improved first, by integrating the heating technology at the heart of the composite material, in order to avoid the use of any external device for the control of the mechanical properties and provide adaptivity in the simultaneous control of the damping and stiffness, and secondly, by providing the ability to control independently several zones in the structure, so that not only static stiffness (as proposed in [23]) but also dynamic damping can be controlled at the same time.

The designed composite structure hence falls in the adaptive structures family, that comes from active control strategies [24, 25]. Here the concept may rather be qualified as semi-active [26, 27] or simply adaptive, since the characteristic time required to pass from one configuration to another (a few seconds) is much larger than the periods associated to the dynamical effects to be controlled. Recent works on damping control of sandwich structures based on magneto-elastic couplings [28, 29], or smart honeycomb composite cores based on shape memory polymers [30] can also be considered as related to the investigations reported here.

The paper is organized as follows. Section 2 introduces the concept of stiffness and damping control through thermo-mechanical couplings. Section 3 presents the practical implementation of the temperature field in the composite structure. Section 4 presents the strategy which has been developed in order to define the optimal configuration for given performances. Section 5 finally illustrates the applicability of the concept through experimental validations, and conclusions are drawn. 
1

2

3

4

5

6

7

8

9

10

In-core heat distribution control for adaptive damping and stiffness tuning of compositestructures3

\section{Control of stiffness and damping}

In this section, the core material which provides the tunability of the structure is first presented, then the layered composite is described.

\subsection{SMP properties}

The methodology which is presented in this paper may be applied with any viscoelastic material that exhibits temperature and frequency dependencies. For this purpose, Shape Memory Polymers are very good candidates since their shape memory properties generally induce a fast transition between the glassy and rubbery states, inducing high loss factor properties during the transition. The viscoelastic material used in this work to tune the structure stiffness and damping is the tBA/PEGDMA polymer (named SMP in the following since it is a Shape Memory Polymer). This SMP has been characterized on a wide band of frequencies and temperatures in [31] and a representative model has been identified in [20]. The temperature and frequency dependencies of the mechanical properties are illustrated in Figure 1. It can be noticed that the loss factor can reach 2.4 at the glass transition which is really significant for damping applications. This figure illustrates the possibility to tune the stiffness and damping properties of the SMP through the temperature, according to the frequency of interest. In the following, this material is used as tunable core in a composite structure.
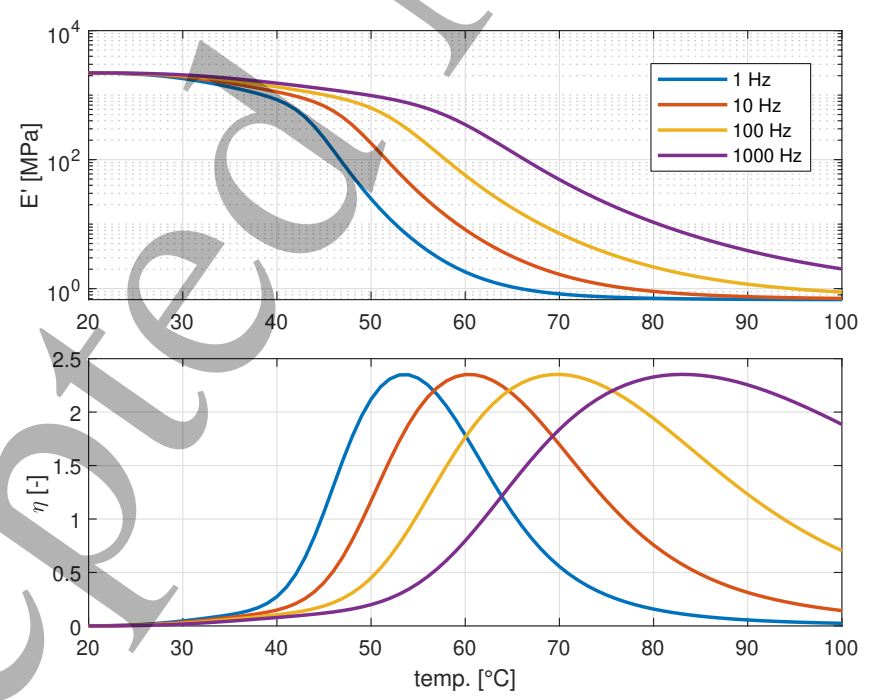

Figure 1. Storage modulus $E^{\prime}$ and loss factor $\eta$ of SMP at various temperatures and frequencies 2.2. Composite structure: damping and stiffness properties

As illustrated in [20], the dynamic behaviour of a simple aluminium-SMP-aluminium sandwich structure can be modified using a homogeneous temperature field: a huge vibration level reduction (up to $80 \mathrm{~dB}$ ) can be obtained on a very wide frequency range 
In-core heat distribution control for adaptive damping and stiffness tuning of compositestructures4

(from 100 to $10000 \mathrm{~Hz}$ ) by heating the structure from $20^{\circ} \mathrm{C}$ to $80^{\circ} \mathrm{C}$. The damping capacities of the SMP are then really impressive, but the reduction of the vibration level is obtained at the price of a loss of static rigidity. In order to overcome this limitation, it is proposed here to apply a non-homogeneous temperature field in the SMP core [32] in order to obtain a compromise between the static and the dynamic behaviours: depending on the local temperature, some zones will provide high static stiffness, while some other zones will bring some damping. Moreover, the technology that is used in this work provides real-time capabilities: the temperature field can be changed according to the expected stiffness and damping distribution.

For illustration purpose, a reduced scale aircraft model is proposed as a composite structure (see Figure 2). The main body of the aircraft model and the brackets used to assemble the components are made of aluminium alloy. The wings are made of multilayered composite: the base skin is made of stainless steel, the core is constituted by the SMP [20] and the top layer is a FR4 composite which is typically used for electronic cards (glass-epoxy composite).

In the next section, the practical implementation of the non-homogeneous temperature field on the aircraft wings is presented.

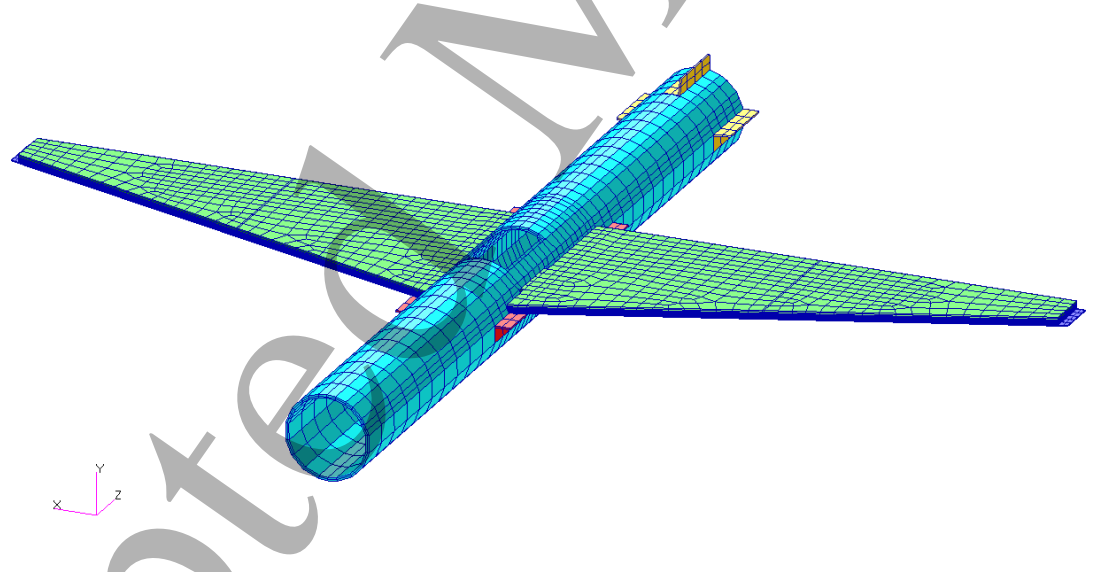

Figure 2. Mesh of the model used for finite elements simulation

\section{Practical implementation of the temperature field}

In order to generate a non homogeneous temperature field in the SMP core, some copper tracks printed on the FR4 board are used to heat the material by Joule effect. This strategy provides the ability to control the spatial distribution of the temperature field: some zones can be designed and printed on the electronic card with independent circuits, each of them being powered by an electric source. The expected temperature field is then constant by zone, and it becomes possible to tune the stiffness and the damping in both space and time. An alternative approach would have consisted in using a single 
source and designing the track with varying width to locally change the resistivity and the resulting heat flux, which is simpler to implement but does not confer any adaptivity property to the structure. An alternative technology to generate the heat flux could be the use of embedded micro fluidic channels [33], but it is probably more intrusive and complex to elaborate. Here, in order to obtain the temperature field of interest, electronic components allowing regulation of the temperature on each zone are embedded on the FR4 board. The heating device is designed according to the procedure defined below, while the definition of the zones will be presented in Section 4 .

\subsection{Model calibration}

Numerical simulations are used to design the heating system that controls the temperature field in the structure. The heat transfer problem is solved for both steady state and transient conditions using the finite element method.

In order to get predictive results, some parameters need to be calibrated. The main material parameters (seê Table 1) are obtained using material datasheets (for aluminium alloy and FR4 composite) or experimental testing (for the SMP).

A two layers composite beam is first manufactured, and used for model calibration. A $0.5 \mathrm{~mm}$ thick aluminium alloy layer is sticked on a $3 \mathrm{~mm}$ thick SMP layer. The heating source is a wire integrated in the SMP and Joule effect from an electric current is used as power source. The imposed constant current intensity and voltage are used to compute the dissipated power by the thermal source.

The temperature field is measured on both sample sides using an infra-red camera. The time evolution of the temperature distribution is then used as reference data for model calibration. In these conditions a $1.15 \mathrm{~W}$ source power leads to a temperature in the range from $30^{\circ} \mathrm{C}$ (far from the source) to $70^{\circ} \mathrm{C}$ (upon the source) on the SMP side and 28 to $33^{\circ} \mathrm{C}$ on the aluminium side.

A 2D finite element model of this sample is then used for calibration. A volume power source is considered in the wire and flux exchanges with the environment are described by a convection law. The convection coefficient with surrounding air, that is 


\section{In-core heat distribution control for adaptive damping and stiffness tuning of compositestructures6}

dependent from the operating environment, together with the location of the source in the wire and its diameter, are used as model updating parameters. This updating is performed on the basis of the temperature distribution on the two sides of the sample. The convection coefficient is calibrated at the value of $5 \mathrm{~W} \cdot \mathrm{m}^{-2} \cdot K^{-1}$ and leads to a confident model which can be used to design the heating system.

\subsection{Temperature field in the composite thickness}

Simulations are performed using the calibrated properties to yerify the capability of the proposed system to impose the temperature in arbitrary zones of the structure. Because of the composite nature of the structure, the temperature is not constant neither in the thickness of the composite, nor in its transverse direction. Since the mechanical properties of the core material are strongly dependent on the temperature, the temperature gradients must be taken into account in the design process.

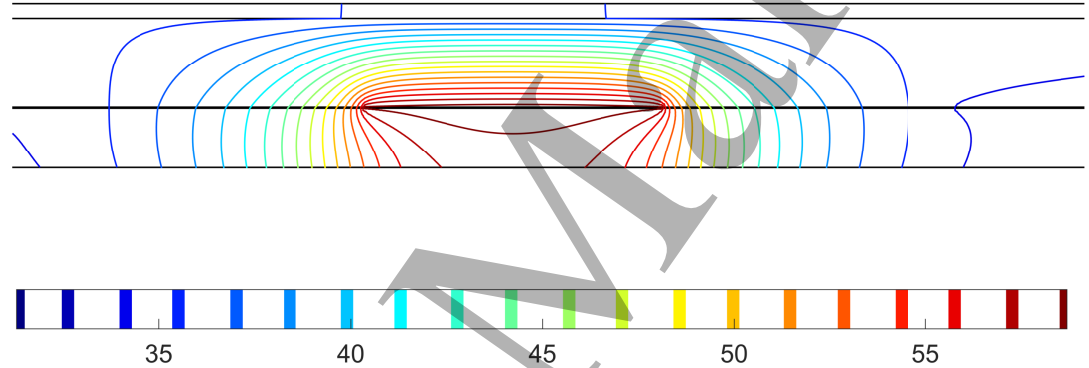

Figure 3. Temperature field computed to determine temperature gradient

Thermal gradient shapes are computed for the composite panel on a reference configuration (see Figure 3) and polynomials functions are used to approximate the temperature field in the thickness while linear transition is assumed between the heating zones. Polynomials functions are then used as inputs in the mechanical model in order to describe the mechanical properties gradients.

\section{Optimal design for damping and static stiffness control}

This section describes the methodology for the definition of the zones on which the temperature is imposed to tune the mechanical properties of the SMP core.

\subsection{Design based on strain energy localisation}

According to [32], a first approach consists in defining zones on the basis of strain energy localisation. Here, the field of interest is 2D, hence using a threshold-based automatic approach is not straightforward. A more qualitative approach is used here and completed by a parametric analysis in order to confirm the ability of the zoning to reach the expected compromise. 
In-core heat distribution control for adaptive damping and stiffness tuning of compositestructures7

A 3D finite element model using 10525 hexadron elements and 158304 degrees of freedom is used for the simulations. The large number of elements comes from the necessity to have 6 elements in the SMP thickness in order to account for thermal gradient in the wing, which has an impact on the mechanical properties of the core.

An aluminum alloy with a Young's modulus of $70 \mathrm{GPa}$, a Poisson's ratio of 0.3 , a density of $2700 \mathrm{~kg} \cdot \mathrm{m}^{-3}$ and a constant loss factor of $\eta=0.001$, is used for the main aircraft body. A stainless steel alloy with a Young's modulus of $210 \mathrm{GPa}$, a Poisson's ratio of 0.27 , a density of $8000 \mathrm{~kg} \cdot \mathrm{m}^{-3}$ and a constant loss factor $\eta=0.001$, is used for the bottom layer of the wings. The top layer of the wing is a FR4 composite with a Young's modulus of $22 \mathrm{GPa}$, a Poisson's ratio of 0.15 , a density of $1900 \mathrm{~kg} . \mathrm{m}^{-3}$ and a constant loss factor $\eta=0.005$. The mechanical properties and the model used for the description of the viscoelastic properties of the SMP corelayer of the wings are detailed in $[20]$.

An eigenfrequency analysis is performed at ambient temperature and the strain energies are post-processed on the wings for modes whose frequency are in range of interest (four modes in the range from 0 to $500 \mathrm{~Hz}$ in this case and the fifth one that is close outside the range) in order to define zones on the wings. As the zones are defined in a $2 \mathrm{D}$ top view of the wings, the strain energy is averaged over the wing thickness and a qualitative monitoring of energy localisation is used to define the zones. The definition of the zones is finally shown in Figure 5, according to the technical requirement that only straight lines have to be used to bound the zones. Using this zoning, all modes shown in Figure 4 are expected to be controlled since their strain energy distributions are maximum in some areas corresponding roughly to one of the zones.
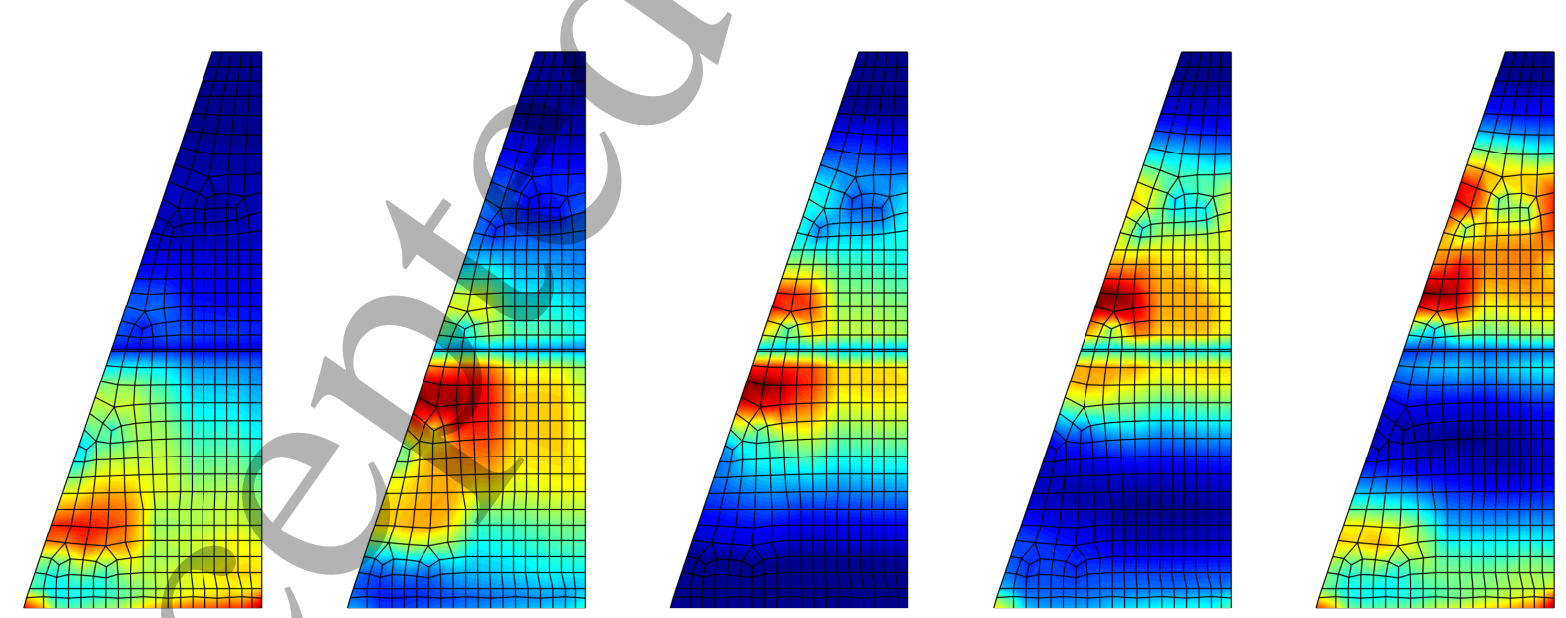

Figure 4. Strain energy (averaged on the thickness) localisation for the first five modes

\subsection{Performance criteria}

In order to check the validity of the zoning for controlling the static and dynamic behaviours of the structure, and then to find an optimal temperature for each zone, 


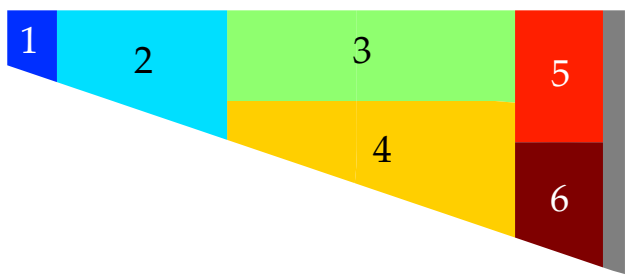

Figure 5. Location of zones IDs on the wings

some performance criteria must be defined. First, the criterion that quantifies the static stiffness is described, then, the criterion associated to the dynamic behaviour is presented.

In order to quantify the static stiffness of the model, a static simulation corresponding to a three-point bending test is considered. The load is applied on the main body of the structure and the end of the wings are simply supported. The deflection at the loading point divided by the value of the applied force is then used as criterion. A low value for this criterion ensures a high static stiffness. As static simulations are performed using a linear solver a unit force loading can be considered and numerical indicator can be expressed as the flexibility at the applied point in $\mathrm{mm} / \mathrm{N}$.

As far as the dynamic behaviour is concerned, free-free boundary conditions are considered, and a frequency response function is computed for a unit point force applied at the end of one of the wings. The associated objective consists in reducing the vibration level on a wide frequency band. To this end, the criterion used in the work is the averaged transverse displacement amplitude of the wings.

This choice has been done after investigation of three other indicators: the amplitude of the peaks in the response function, the damping factor for each peak evaluated using a $-3 \mathrm{~dB}$ bandwidth approach and a global equivalent loss factor based on strain energy repartition. The two first indicators provided interesting results because they can be used to focus on a specific set of modes and to analyse separately the effect of a temperature field on each mode. However, in order to obtain reliable results, the computation of the maximum values requires an adaptive refinement process to find the exact location of the peaks, which results in an increase of the computation time for each temperature set. Another limitation of these two methods is linked to the very good dissipating capability of the SMP at some temperatures that leads to very flat curves (see red curve in Figure 9) where peak amplitude computation and bandwidth method used for damping evaluation are not significant anymore. The last method consists in computing an equivalent loss factor for the wing:

$$
\eta_{\mathrm{eq}}=\left\langle\frac{\int_{\text {wing }} w_{s}(x, y, z) \eta(x, y, z) \mathrm{d} x \mathrm{~d} y \mathrm{~d} z}{\int_{\text {wing }} w_{s}(x, y, z) \mathrm{d} x \mathrm{~d} y \mathrm{~d} z}\right\rangle
$$

where $w_{s}$ is the strain energy density and $\langle\cdot\rangle_{\Delta f}$ is the average over the frequency range of interest $\Delta f$. Whereas the two first criteria are dependent of the modal 
In-core heat distribution control for adaptive damping and stiffness tuning of composite structures9

behaviour of the structure, this criterion is independent and requires less evaluations over the frequency range: a refinement study of the sampling in the frequency range shows that only a reduced number of evaluation points are necessary to reach stability of the criterion: in the considered case, only 13 evaluations over the frequency range were required, while 80 to 100 were needed for the two first criteria (due to refinement near the peaks to perform precise calculation).

A comparative study of all dynamic criteria shows similar evolution patterns with temperature. The one which is reported here is based on the equivalent loss factor defined by equation (1). In order to have a value which is minimal for an optimal configuration, the criterion equal to $-\log \left(\eta_{\mathrm{eq}}\right)$ is considered in the analysis.

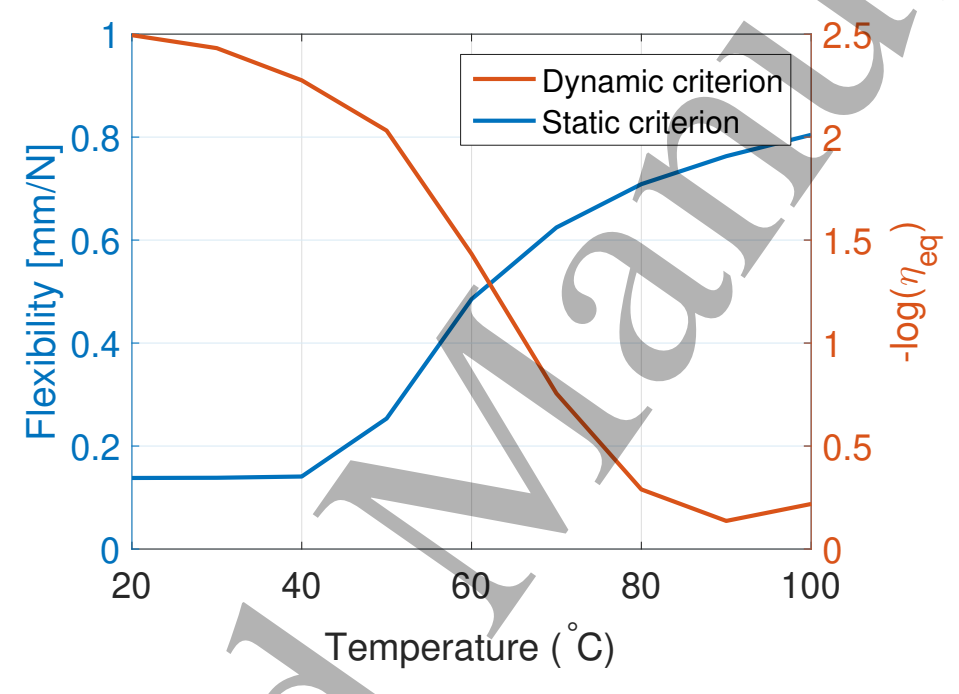

Figure 6. Evolution of the stiffness and the damping of the wing according to the temperature of the SMP core.

The evolution of the static and the dynamic criteria with temperature is presented in Figure 6: here, the same temperature is imposed on all zones (a temperature gradient in the thickness of the wing is however considered). As expected, the static and dynamic criteria are conflicting: the static stiffness decreases when damping capability increase. A kind of compromise between the static and the dynamic behaviour can be observed between 60 and $70^{\circ} \mathrm{C}$. In thé next section, independent temperatures are considered on all zones, in order to reach a better configuration.

\subsection{Parametric investigation}

In order to cover the whole temperature range for each zone, a design of experiment (DOE) is performed using a latin hypercube sampling algorithm. 500 sets of temperatures are used to compute both static and dynamic responses and evaluate the criteria presented above. The ambient temperature is considered to be $25^{\circ} \mathrm{C}$ and temperatures of each zone are sampled in a ratio from 1 to 3.5 (giving zones temperature in the range from $25^{\circ} \mathrm{C}$ to $87.5^{\circ} \mathrm{C}$ ). 
A first post-processing of the results of the DOE consists in analysing the scatterplots shown in Figure 7, where T\# refers to the temperature of zone \#. Each plot shows the value of the two criteria (dynamic in blue, static in green) versus the value of temperature of one zone. For a single value of the temperature of a given zone, several points appear since the temperatures of the other zones are varied. This is an easy way to identify the global effect of a given parameter (the temperature of a given zone) on a given criterion.

From these scatterplots, it can be concluded that the temperature in zones 2,3 and 4 are important parameters: whatever is the temperature in the other zones, if temperature in zone 2 is in the upper values of the range, then the dynamic criterion is in the minimum zone and if the temperature is in the lower values of the range, then the static criteria is in the minimum zone. As this observation is true for 3 zones, alternating high and low temperatures in zones 2, 3 and 4 may lead to solutions that minimize both criteria and then satisfy both high damping and high static stiffness.

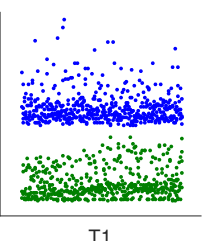

$\mathrm{T} 1$

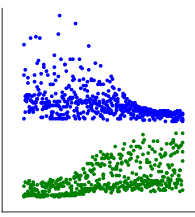

$\mathrm{T} 2$
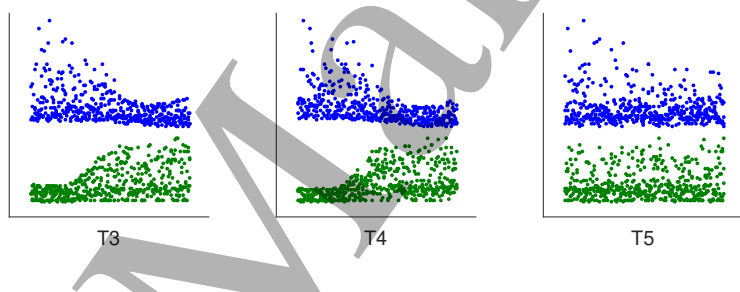

T5

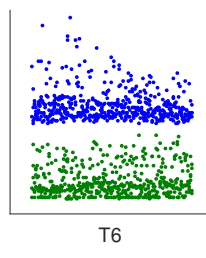

Figure 7. Criteria as a function of temperature in the different zones (blue: dynamic, green: static). Linear scales from $25^{\circ} \mathrm{C}$ to $87^{\circ} \mathrm{C}$ are used for all temperatures.

This preliminary analysis confirms that the zoning should be able to reach the expected compromise.

This is confirmed by the Pareto front (see Figure 8), where the dynamic criterion is plotted as a function of the static one. Samples corresponding to the best static behavior (highlighted in red in Figure 8) are found for temperature values corresponding to the glassy state for zones 2, 3 and 4, while samples minimizing the dynamic criteria (highlighted in blue in Figure 8) are found for temperature above the glass transition for T2, T3 and T4. A common characteristic is found for samples minimizing both criteria (highlighted in green in Figure 8): temperatures T2, T3 and T4 are toggling between both states while temperatures for zones 1, 5 and 6 vary in the full range.

To move toward experimental validation, 3 temperature sets (see Table 2) were chosen among the 33 configurations: high static stiffness and low damping capability (one of the blue sets in Figure 9), low static stifness but high damping capability (one of the red sets in Figure 9) and a compromise in the Pareto front (one of the green sets in Figure 9). These 3 sets will be experimentally studied in the following section. The precise location of the sets on the Pareto front is shown in Figure 9. In this figure, the dynamic response of the three sets is also presented (the static deflection can be directly extracted from the Pareto front). The peak corresponding to the first mode is the more difficult to reduce due to similar deformation shape between the first mode shape 
1

2

3

4

5

6

7

8

9

\section{In-core heat distribution control for adaptive damping and stiffness tuning of compositestructures11}
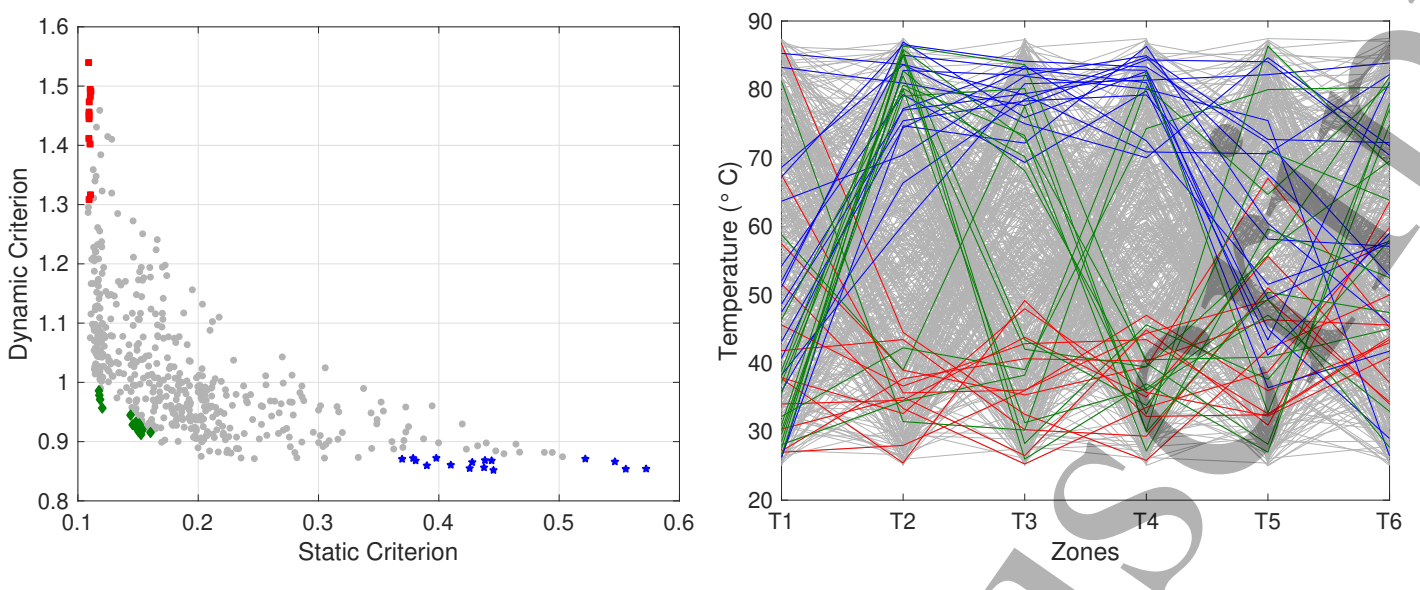

Figure 8. Pareto front (left) and corresponding temperatures (right)

\begin{tabular}{|c|c|c|c|c|c|c|}
\hline Set & $T_{1}$ & $T_{2}$ & $T_{3}$ & $T_{4}$ & $T_{5}$ & $T_{6}$ \\
\hline 1 & $27^{\circ} \mathrm{C}$ & $27^{\circ} \mathrm{C}$ & $36^{\circ} \mathrm{C}$ & $47^{\circ} \mathrm{C}$ & $36^{\circ} \mathrm{C}$ & $43^{\circ} \mathrm{C}$ \\
\hline 2 & $52^{\circ} \mathrm{C}$ & $85^{\circ} \mathrm{C}$ & $83^{\circ} \mathrm{C}$ & $81^{\circ} \mathrm{C}$ & $45^{\circ} \mathrm{C}$ & $29^{\circ} \mathrm{C}$ \\
\hline 3 & $31^{\circ} \mathrm{C}$ & $85^{\circ} \mathrm{C}$ & $26^{\circ} \mathrm{C}$ & $37^{\circ} \mathrm{C}$ & $27^{\circ} \mathrm{C}$ & $78^{\circ} \mathrm{C}$ \\
\hline
\end{tabular}

Table 2. Temperatures for the 3 characteristic sets of Figure 9

and the static deflection, but, as a perspective, temperature sets that are dominant on the first mode damping could be investigated, As various solutions provide acceptable results, another step in this study could be/to perform sensitivity studies for different temperature sets providing compromise between the two criteria to find which sets are the most robust to uncertainties in order to ensure good results when uncertainties occur, in particular in the temperature field.
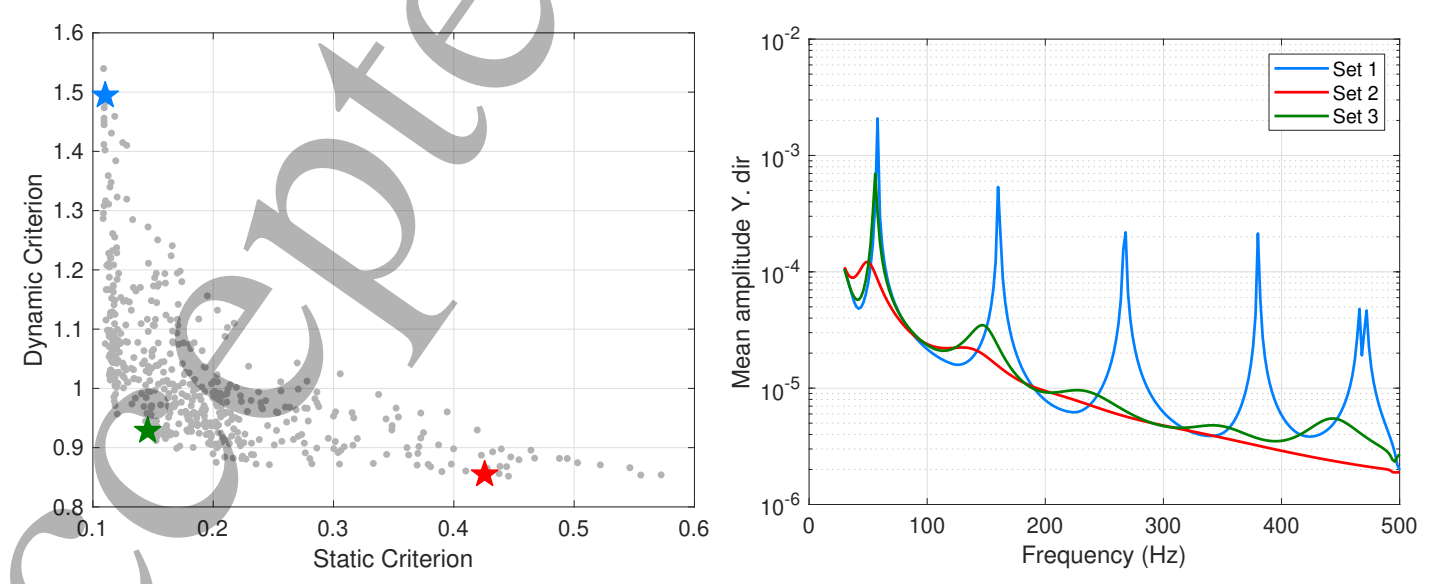

Figure 9. Sets of temperatures in the features space, with highlighted implemented ones (left) and associated dynamic responses (right), mean amplitude of transverse displacement on the wings 


\section{In-core heat distribution control for adaptive damping and stiffness tuning of compositestructures12}

\section{Experimental validation}

In order to validate the concept, the three sets of temperature chosen during the optimization procedure presented in section 4 are reproduced experimentally in this section. For each configuration, two experimental runs are performed: a static test to check the stiffness of the aircraft model, and a dynamic test to verify the damping behaviour of the structure. The temperature field on the wings is monitored during the experiments to check the quality of the regulation.

\subsection{Temperature field measurement}

The temperature of the 12 zones is measured at the center of each zone with an embedded sensor (DS1822), a PID regulation is performed with an Arduino ${ }^{\mathrm{TM}}$ system located in the fuselage (see Figure 10), and the heating is obtained by a power supply (24 Volts, $10 \mathrm{~A})$. The temperature field on the wings is checked by infrared thermography using a CEdip Jade III MWIR camera. The measurements are done on the external surface of the FR4 board.

The time evolution of the temperature measured by the embedded sensors is shown in Figure 11. In this case, the expected temperature field corresponds to set 3 (see Table 2 ). The PID regulation is efficient, since the thermal target in the critical zones (2 and 4 in particular) is reached in a few seconds: in less than 2 seconds, the steady state is reached on zones 2 and 4, while 10 seconds are necessary for the other zones. The regulation of the temperature in zone 1 is slower because of its smaller size, while for zones 5 and 6 , the proximity to the main body of the structure implies more thermal conduction which also slowers the regulation. However, the expected temperature distribution is obtained in all casses, as seen in Figure 12. It can be observed that the homogeneity of the temperature field is quite good and that the zones are heated as expected. The time required to change from one set to another is dependent on the relative temperature field target: heating is quite fast (a few seconds), while cooling may take few minutes since no specific device is embedded in this system to this end.

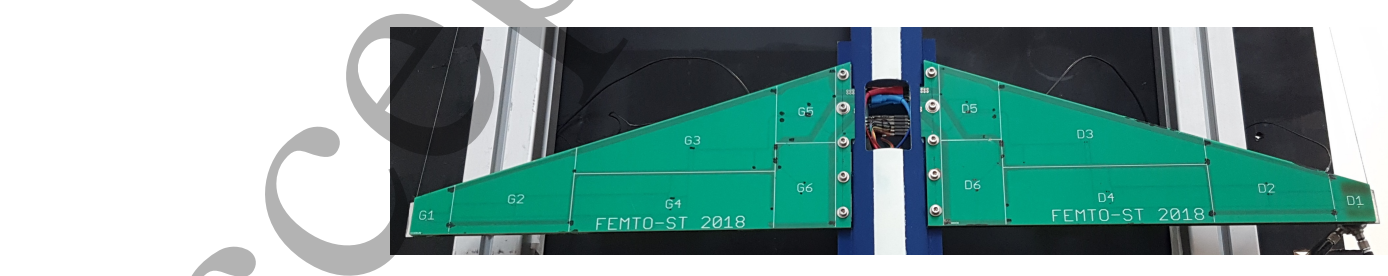

Figure 10. View of the aircraft model: 6 zones identified on each wing and controlled by an Arduino ${ }^{\mathrm{TM}}$ system inside the fuselage. 
In-core heat distribution control for adaptive damping and stiffness tuning of composite structures13

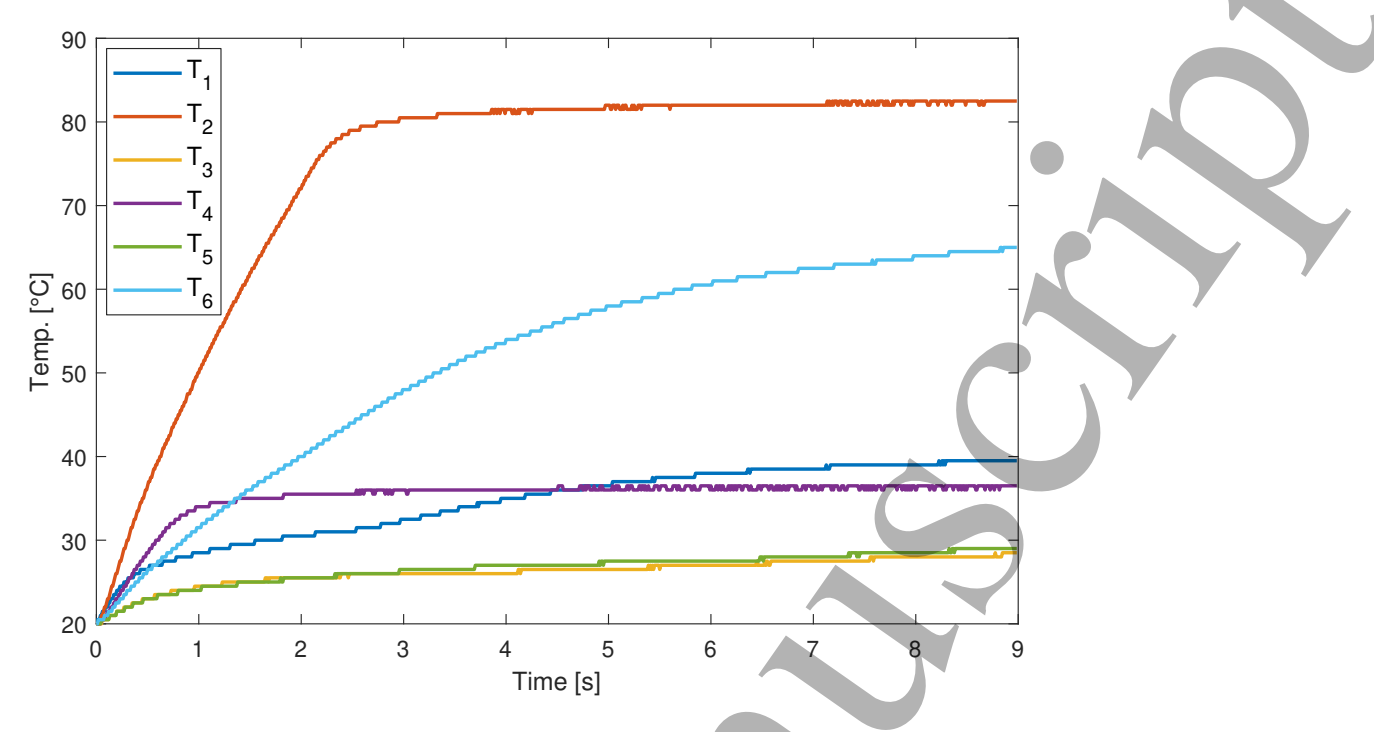

Figure 11. Temperature control for the set 3 for each zone, measured from the Arduino $^{\mathrm{TM}}$ controler.

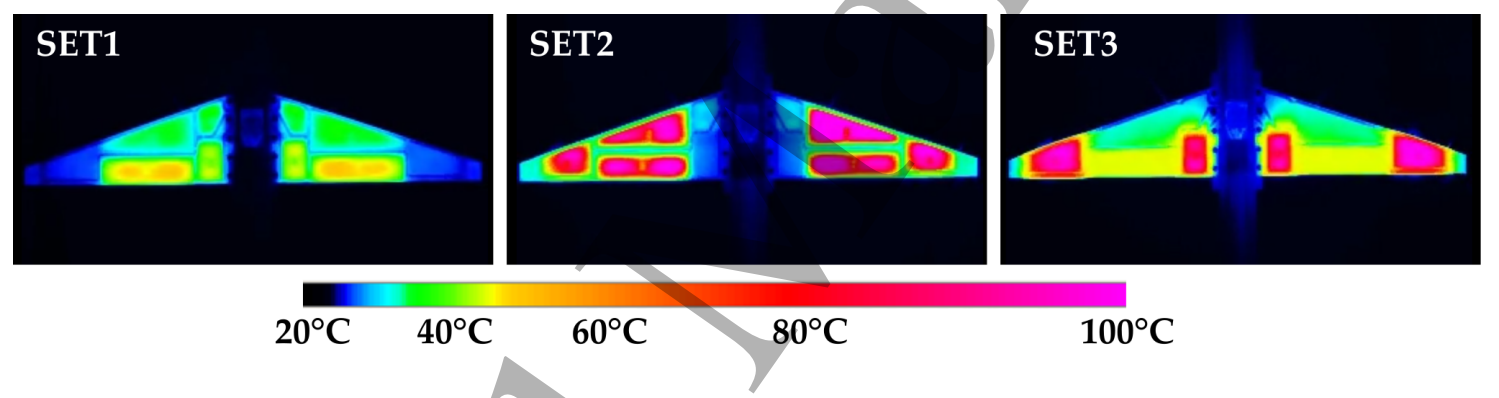

Figure 12. Temperature field measured for the three sets (Table 2).

\subsection{Static experimental validation}

In order to measure the stiffness of the structure for each set of temperatures, a static bending test is used. A universal testing machine MTS is used. A displacement at $1 \mathrm{~mm} / \mathrm{min}$ is applied in the middle of the fuselage and the structure is supported at the end on the wings as shown in Figure 13. For each set the deflection is measured with a Micro Epsilon triangulation laser sensor, located under the fuselage. The maximum force applied on the structure is $2 \mathrm{~N}$ (load cell K25 from Scaime). The linearity is verified and the results in terms of flexibility are provided in Figure 14.

The model presents a higher rigidity than the experimental setup, this can be explained by the assumption of a perfect assembly between the wings and the fuselage in the model. Nevertheless the experimental tests and the numerical results are coherent and the measured relative properties of the structure for the three investigated sets are in accordance with the expected ones. Set 1 provides the highest static stiffness. Indeed for this'set, the temperature on each zone is smaller than the SMP glass transition temperature, and then the storage modulus of the sandwich core is high. Regarding Set 2, the temperature is mainly above the SMP glass transition temperature and the stiffness of the structure is lower. Set 3, which corresponds to the compromise between 


\section{In-core heat distribution control for adaptive damping and stiffness tuning of compositestructures14}

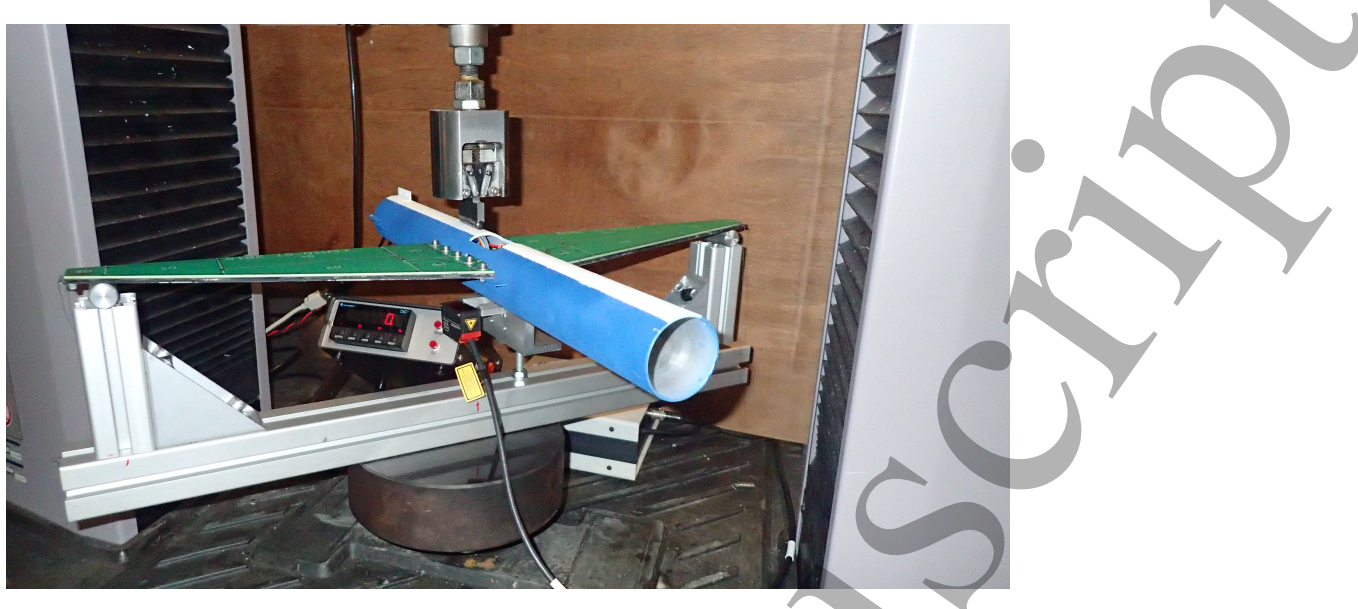

Figure 13. View of the static experimental setup

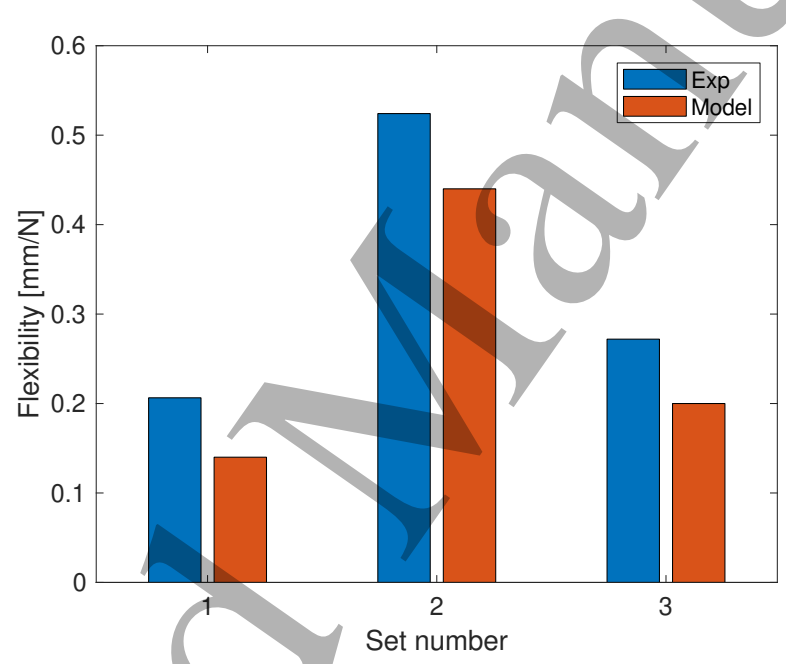

Figure 14. Flexibility $(\mathrm{mm} / \mathrm{N})$ for the three temperature field sets, comparison between the model and the experimental tests.

static and dynamic behaviours according to the optimization procedure, has a static stiffness criterion which is only increased by $20 \%$ compared to the best single-criteria configuration.

\subsection{Dynamic experimental validation}

The experimental setup for the vibration tests is shown in Figure 15. The structure is suspended with springs and wires. An electrodynamic shaker is used to excite the structure, located at the end of the wing. An impedance head is used to measure the input force and the acceleration at the input point. A scanning vibrometer is used to measure the velocity of the aircraft model, based on a mesh of 36 points (15 on each wing and 6 on the fuselage).

The measured FRFs are presented in Figure 16. The computation of the mean transverse displacement is performed on the 30 measurement points located on the 


\section{In-core heat distribution control for adaptive damping and stiffness tuning of composite structures15}

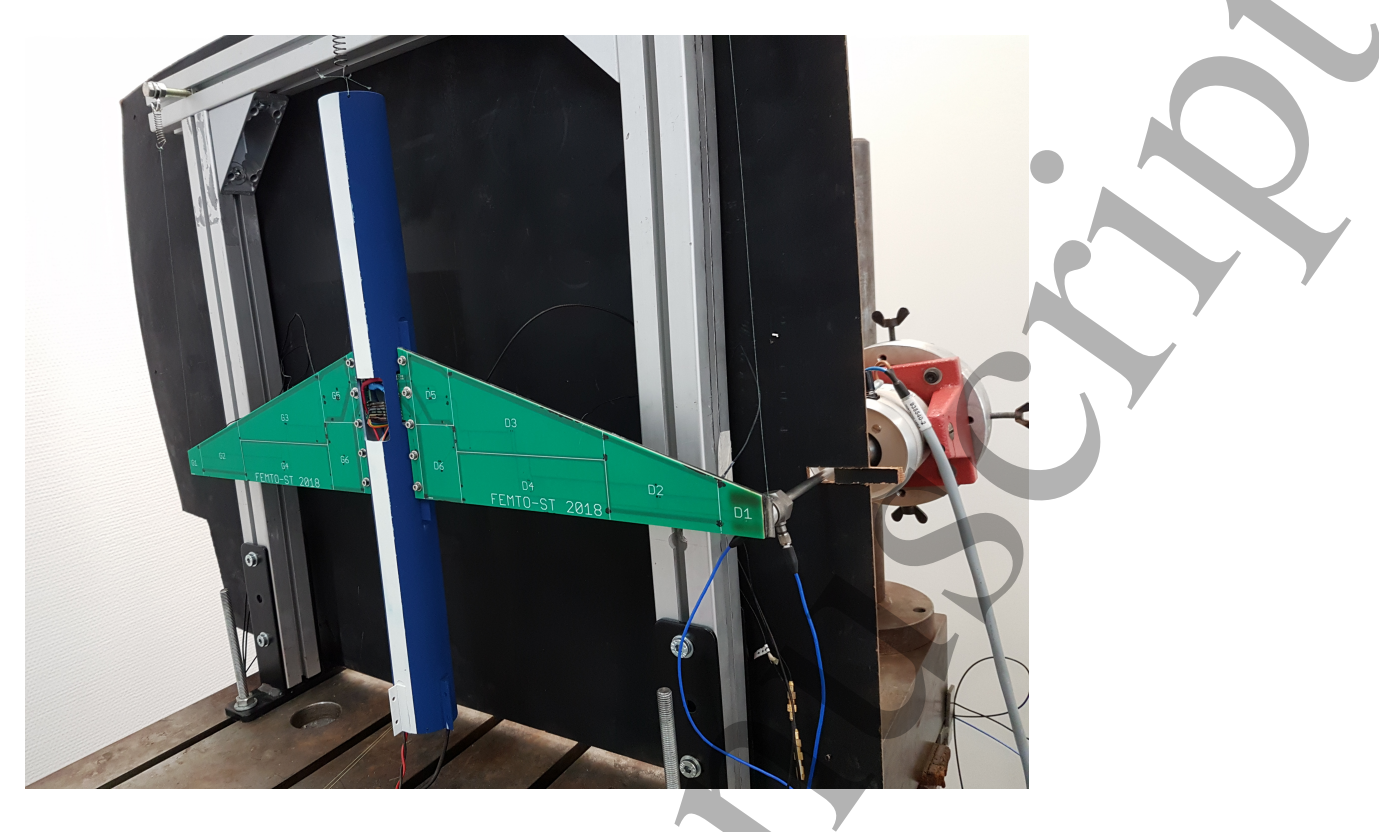

Figure 15. View of the dynamic experimental setup

wings, which is slightly different from the averaged value computed with the model that considers the whole volume of the wings. Some discrepancies can be observed between the model and the experimental tests which can be due to some assumptions in the model (perfect gluing of the sandwich, perfect fuselage-wings assembly) on the one hand, and to the experimental defects (boundary conditions, shaker attachment) on the other hand. However, the experimental results are in strong coherence with the numerical predictions. The vibration leyels at resonances are dramatically reduced for Set 2, while the best compromise between the dynamic behaviour and the static stiffness is obtained with the temperature field corresponding to Set 3. The effect on the first mode is clearly visible, with only a small reduction of the amplitude compared to Set 1. The static tests are fully in accordance with this observation.

\section{Conclusions}

In this work, a smart composite structure with damping and stiffness control ability is proposed and illustrated on a reduced scale aircraft. The multilayered arrangement of the composite structure includes a shape memory polymer core, whose damping and stiffness are tuned by temperature control. The structure is divided in six zones, each of them can be heated in real time using temperature regulation to obtain a non-homogeneous temperature field inducing spatial distribution of the mechanical properties. The heat flux is provided by copper tracks printed on an electronic board used as skin of the sandwich. The application of the model-based design process described above, which includes thermal and mechanical simulations steps, results in the definition of several temperature distribution sets that correspond to very different dynamical behaviours. When the wings' temperature is kept under the glass transition 


\section{In-core heat distribution control for adaptive damping and stiffness tuning of composite'structures 16}

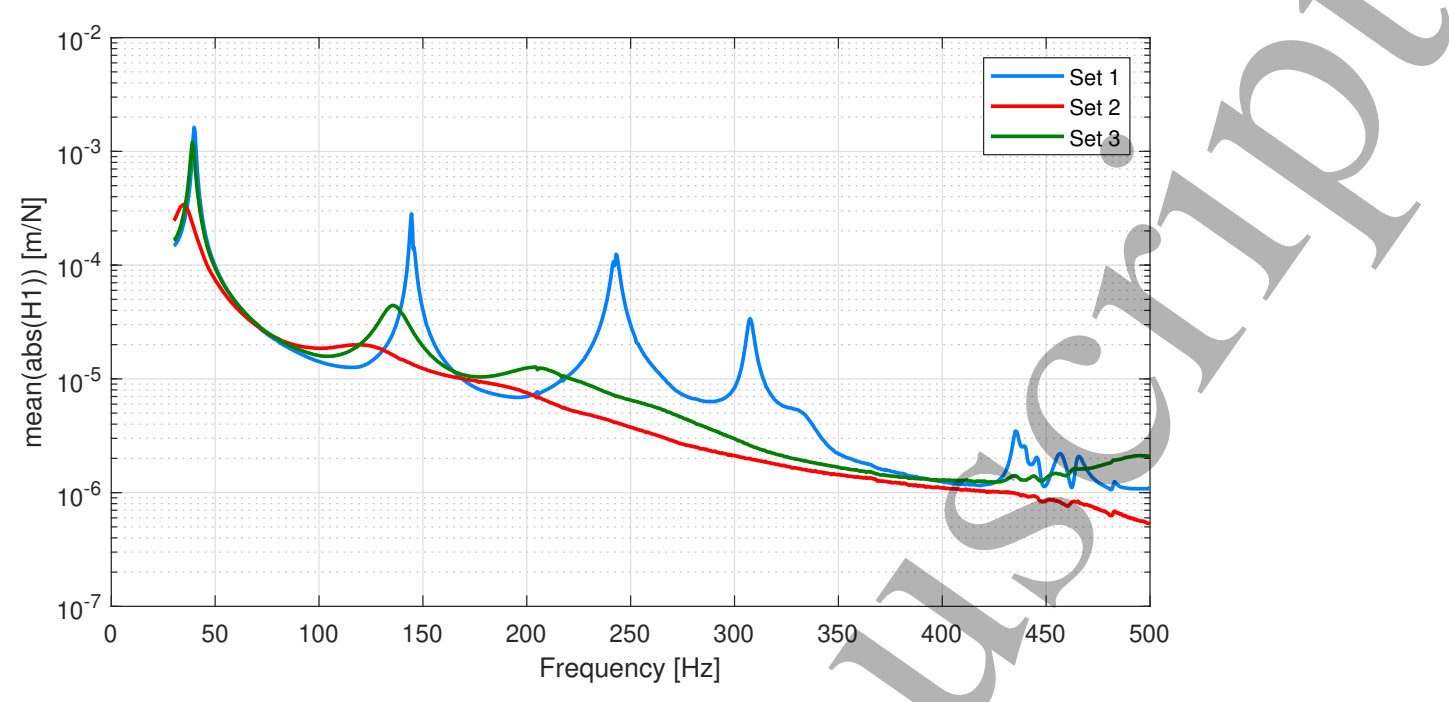

Figure 16. Experimental results: measured FRFs for the three sets.

temperature of the SMP core, the composite structure has a very high static stifness, while the resonances are highly marked because of the low resulting structural loss factor. The damping and the stiffness can be changed in less than 10 seconds, by heating the wings. In this case, the static stiffness is reduced but the dynamic response of the structure is drastically damped. A compromise between static and dynamic behaviours is found with a non-homogeneous field of temperatures. The prototype which has been used for the tests has the ability to be controlled in real time, and the three configurations of interest have shown to be well correlated with the models, leading to the validation of the concept.

\section{Acknowledgments}

The authors would like to acknowledge Eric Joseph and Thomas Jeannin for their contribution to the experimental part of the work. This work has been funded by ANR (contract ANR-17-CE08-0035 ETNAA), in collaboration with EIPHI Graduate School (ANR-17-EURE-0002). The authors would like to acknowledge the "Bourse L'Oréal UNESCO Pour les Femmes et la Science" program that aim to improve the position of women in science.

\section{References}

[1] Ferry J D and Ferry J D 1980 Viscoelastic properties of polymers (John Wiley \& Sons)

[2] Rao M D 2003 Journal of Sound and Vibration 262457 - 474

[3] Grootenhuis P 1970 Journal of Sound and Vibration 11 421-433

[4] Araujo A, Soares C M, Soares C M and Herskovits J 2010 Composite Structures 922321 - 2327 ISSN 0263-8223

[5] Lifshitz J and Leibowitz M 1987 International Journal of Solids and Structures 23 1027-1034

[6] Li J and Narita Y 2012 Journal of Vibration and Control 1077546312463756 
1

2

3

4

5

6

7

8

9

In-core heat distribution control for adaptive damping and stiffness tuning of composite structures 17

[7] Berthelot J M, Assarar M, Sefrani Y and El Mahi A 2008 Composite Structures 85189 - 204 ISSN 0263-8223

[8] Ege K, Roozen N, Leclere Q and Rinaldi R G 2018 Journal of Sound and Vibration 426 129-149

[9] Kpeky F, Akoussan K, Abed-Meraim F and Daya E M 2018 Composite Structures $183611-619$

[10] Tsai Y, Tai C h, Tsai S J and Tsai F J 2008 European Polymer Journal 44 550-554

[11] Barwood M J, Breen C, Clegg F and Hammond C L 2014 Applied Clay Science 102 41-50

[12] Caputo M and Mainardi F 1971 La Rivista del Nuovo Cimento (1971-1977) 1 161-198

[13] Lakes R S 1998 Viscoelastic solids vol 9 (CRC press)

[14] Chang K C, Soong T, Oh S T and Lai M 1992 Journal of Structural Engineering 118 1955-1973

[15] Sefrani Y and Berthelot J M 2006 Composites Part B: Engineering 37 346-355

[16] Lesieutre G A and Govindswamy K 1996 International Journal of Solids and Structures 33419-432

[17] Millithaler P, Dupont J B, Ouisse M, Sadoulet-Reboul E and Bouhaddi N 2017 Journal of Sound and Vibration 407 191-208

[18] Bai Y, Yu K, Zhao J and Zhao R 2018 Composite Structures 201 816-827

[19] Jaboviste K, Sadoulet-Reboul E, Peyret N, Arnould C, Collard E and Chevallier G 2019 Mechanical Systems and Signal Processing 119 65-80

[20] Butaud P, Foltête E and Ouisse M 2016 Composite Structures 153 401-408

[21] Billon K, Ouisse M, Sadoulet-Reboul E, Collet M, Butaud P, Chevallier G and Khelif A 2019 Smart Materials and Structures

[22] Ouisse M, Renault D, Butaud P and Sadoulet-Reboul E 2019 Journal of Sound and Vibration 454 $63-72$

[23] McCoul D, Rosset S, Besse N and Shea H 2016 Smart Materials and Structures 26025015

[24] Fuller C C, Elliott S and Nelson P A 1996 Active control of vibration (Academic Press)

[25] Inman D J 2017 Vibration with control (John Wiley \& Sons)

[26] Collet M, Ouisse M and Tateo F 2014 IEEE Sensors Journal 14

[27] Ouisse M, Collet M and Scarpa F 2016 Smart Materials and Structures 25115016

[28] Irazu L and Elejabarrieta M J 2018 Materials \&5 Design 140 460-472

[29] Irazu L and Elejabarrieta M 2019 Smart Materials and Structures 28075022

[30] Tao R, Yang Q S, Zhang X J, Liu X, He, X Q and Liew K M 2018 Journal of Applied Polymer Science 13545672

[31] Butaud P, Ouisse M, Placet V, Renaud F, Travaillot T, Maynadier A, Chevallier G, Amiot F, Delobelle P, Foltête E and Rogueda-Berriet C 2018 Polymer Testing 69

[32] Butaud P, Ouisse M, Chevallier G and Foltête E 2017 Design of thermally adaptive composite structures for damping and stiffness control SPIE Smart Structures NDE, Behavior and Mechanics of Multifunctional Materials and Composites 2017 vol 10165 (International Society for Optics and Photonics) p 101650T

[33] Coppola A M, Griffin A S, Sottos N R and White S R 2015 Composites Part A: Applied Science and Manufacturing $\mathbf{7 8} 412-423$

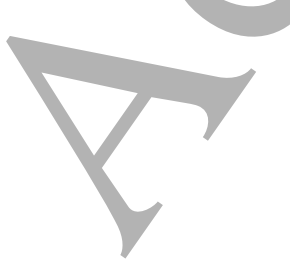

